\title{
Management of initial colonisations with Burkholderia species in France, with retrospective analysis in five cystic fibrosis Centres: a pilot study
}

Vianney Gruzelle ${ }^{1} \mathbb{D}$, Hélène Guet-Revillet ${ }^{2,3}$, Christine Segonds ${ }^{3}$, Stéphanie Buii ${ }^{4}$ Julie Macey ${ }^{5}$, Raphaël Chiron ${ }^{6}$, Marine Michelet ${ }^{1}$, Marlène Murris-Espin ${ }^{7}$ and Marie Mittaine ${ }^{1 *}$

\begin{abstract}
Background: Whereas Burkholderia infections are recognized to impair prognosis in cystic fibrosis (CF) patients, there is no recommendation to date for early eradication therapy. The aim of our study was to analyse the current management of initial colonisations with Burkholderia cepacia complex (BCC) or B. gladioli in French CF Centres and its impact on bacterial clearance and clinical outcome.

Methods: We performed a retrospective review of the primary colonisations (PC), defined as newly positive sputum cultures, observed between 2010 and 2018 in five CF Centres. Treatment regimens, microbiological and clinical data were collected.

Results: Seventeen patients (14 with BCC, and 3 with B. gladioli) were included. Eradication therapy, using heterogeneous combinations of intravenous, oral or nebulised antibiotics, was attempted in 11 patients. Six out of the 11 treated patients, and 4 out of the 6 untreated patients cleared the bacterium. Though not statistically significant, higher forced expiratory volume in 1 second and forced vital capacity at PC and consistency of treatment with in vitro antibiotic susceptibility tended to be associated with eradication. The management of PC was shown to be heterogeneous, thus impairing the statistical power of our study. Large prospective studies are needed to define whom to treat, when, and how.
\end{abstract}

Conclusions: Pending these studies, we propose, due to possible spontaneous clearance, to check the presence of Burkholderia 1 month after PC before starting antibiotics, at least in the milder cases, and to evaluate a combination of intravenous beta-lactam + oral or intravenous fluoroquinolone + inhaled aminoglycoside.

Keywords: Burkholderia cepacia complex, BCC, Burkholderia gladioli, Cystic fibrosis, Eradication

\footnotetext{
* Correspondence: mittaine.m@chu-toulouse.fr

'CRCM pédiatrique, Service de Pneumo-Allergologie pédiatrique, Hôpital des

Enfants, Centre Hospitalier Universitaire de Toulouse, 330 avenue de

Grande-Bretagne - TSA 40031, 31059 Toulouse cedex 9, France

Full list of author information is available at the end of the article
}

(c) The Author(s). 2020 Open Access This article is licensed under a Creative Commons Attribution 4.0 International License, which permits use, sharing, adaptation, distribution and reproduction in any medium or format, as long as you give appropriate credit to the original author(s) and the source, provide a link to the Creative Commons licence, and indicate if changes were made. The images or other third party material in this article are included in the article's Creative Commons licence, unless indicated otherwise in a credit line to the material. If material is not included in the article's Creative Commons licence and your intended use is not permitted by statutory regulation or exceeds the permitted use, you will need to obtain permission directly from the copyright holder. To view a copy of this licence, visit http://creativecommons.org/licenses/by/4.0/ The Creative Commons Public Domain Dedication waiver (http://creativecommons.org/publicdomain/zero/1.0/) applies to the data made available in this article, unless otherwise stated in a credit line to the data. 


\section{Background}

The Burkholderia cepacia complex (BCC) is a group of 22 closely related species belonging to the Burkholderia genus, which are capable of colonising and infecting the respiratory epithelium of cystic fibrosis (CF) patients. Though asymptomatic carriage is possible, BCC organisms are associated with a marked increase in morbiditymortality rates, due to rapid decline in lung function, extensive pneumopathy with life-threatening septicaemia (cepacia syndrome), as well as to poor lung transplantation outcomes [1-3]. B. cenocepacia and B. multivorans are the main species involved in North America and most European countries including France [3-6], whereas a high prevalence of $B$. contaminans is observed in IberoAmerican countries [7]. In the Iberian Peninsula, B. cepacia and B. stabilis are more frequent than in other European countries $[8,9]$. Several studies demonstrated faster clinical deterioration, as well as lower survival after transplantation in patients harbouring B. cenocepacia compared to those harbouring $B$. multivorans $[2,3,10,11]$. However, the spread of the ST180 strain of B. multivorans in a French CF Centre resulted in numerous cepacia syndromes and deaths (French Observatoire Burkholderia cepacia (OBC) data). The impact of other species of the BCC is less documented, though adverse outcomes have also been reported [7, 12]. In the 1990s, highly transmissible and often highly virulent strains were responsible for large outbreaks within CF communities [13-15]. Following the implementation of infection control measures, patient-to-patient transmission decreased, and the distribution of BCC species was hence modified. Thus, in countries where B. cenocepacia was the most common species in the 1990s due to epidemic spread, $B$. multivorans currently outweighs $B$. cenocepacia in new infections $[3,5,6]$. The impact of $B$. gladioli colonisation is less clear, but abscesses and bacteraemia following lung transplantation have been reported [16, 17]. In Europe and the United States, the current prevalence and incidence of $\mathrm{BCC}$ infections are about 2 and $0.5 \%$, respectively, whereas the prevalence of B. gladioli is below $0.5 \%[4,6]$.

Early eradication therapy of Pseudomonas aeruginosa has been clearly proven to be a successful strategy to postpone chronic infection. Conversely, studies evaluating the treatment of newly acquired BCC colonisations, given their low incidence, are sparse and based on isolated case reports or small series, which are often inconclusive [18]. There are no recommendations either concerning the even rarer B. gladioli, though it is one of the most troublesome species during the peritransplantation period. Moreover, Burkholderia species are multi-drug resistant, which limits therapeutic options, and in vitro susceptibility testing is considered to be poorly reliable [19].
In this context, the aim of this preliminary study was to evaluate the current approach to new infections with Burkholderia in France, and the impact of potential eradication treatment on bacterial clearance and pulmonary outcomes. We present a 2010-2018 retrospective study in five CF Centres, including 17 patients.

\section{Methods}

\section{Ethics statement}

The data collection process was reported to the Commission Nationale Informatique et Liberté (French Data Protection Authority) on 26/01/2018, under number 2146344v0.

\section{Patient recruitment and data collection}

Five French CF Centres (3 paediatric and 2 adult Centres), located in Toulouse, Montpellier and Bordeaux, as well as the French $\mathrm{OBC}$ participated in the present pilot study. In all Centres, the microbiological analysis of sputum samples was performed using a selective medium and a low detection level for Burkholderia species, according to the guidelines of the French Society for Microbiology [20]. Patients who acquired BCC or $B$. gladioli between 01/01/2010 and 01/01/2018 were considered for retrospective analysis. The absence of Burkholderia from all sputum cultures during the two prior years was required for inclusion. The date of primary colonisation (PC) was defined as the date of the first positive sputum culture, and the primary isolate had to have been sent to the $\mathrm{OBC}$ for analysis. Patient data were collected retrospectively from computerised regional registers and medical records in each CF Centre. Baseline characteristics included gender, age, CFTR (Cystic Fibrosis Transmembrane conductance Regulator) genotype, body mass index (BMI), best forced vital capacity (FVC) and best forced expiratory volume in $1 \mathrm{sec}-$ ond (FEV1), as well as exocrine pancreatic insufficiency, insulin-dependent diabetes, nutritional support, liver cirrhosis, allergic broncho-pulmonary aspergillosis (ABPA), and need for systemic antibiotic treatment or corticotherapy in the 3 months preceding PC. To assess lung function evolution, the FEV1 values 2 years after PC were recorded.

Microbiological data included the co-pathogens at PC (Pseudomonas aeruginosa, methicillin-susceptible and methicillin-resistant Staphylococcus aureus, Achromobacter spp., Stenotrophomonas maltophilia, Fungi and Mycobacteria), the number of sputum cultures performed during the 2 years preceding and the 2 years following PC, as well as the dates of the last positive and of the first negative cultures. The Burkholderia strains that were recovered only once (from the PC sputum), and never during the follow-up period, were defined as single isolates. 
When eradication therapy directed against Burkholderia was implemented, onset date, molecules used, routes of administration, and duration were recorded.

\section{Strain analysis}

Identification of the primary and potential subsequent isolates to the species-level was determined by the OBC, using ARDRA (Amplified Ribosomal DNA-Restriction Analysis) [17, 21], or $\operatorname{RecA}$ gene sequencing [22]. Strain analysis of $\mathrm{BCC}$ isolates was complemented by genotyping to assess $\mathrm{BCC}$ cross-transmission if relevant, i.e. if the same species had been recovered from at least one other patient in the same CF Centre within the 3 preceding years. Besides, all B. cenocepacia and B. multivorans isolates were compared to the highly transmissible strains identified in France.

Once data collection had been completed, the susceptibility of the last strain recovered before the onset of treatment was tested by the $\mathrm{OBC}$, for each antibiotic administered, following the guidelines of the antibiogram committee of the French Society for Microbiology, by means of the disk diffusion test (piperacillin-tazobactam, cotrimoxazole), or the epsilometer test (ceftazidime, temocillin, aztreonam, levofloxacin, ciprofloxacin). Results were interpreted using PK-PD breakpoints, or species related breakpoints when available [23]. In the absence of specific values for inhaled aztreonam-lysine, the breakpoints for parenteral administration were used, whereas inhaled tobramycin was considered active given the high pulmonary concentrations delivered [24, 25]. The consistency of eradication treatments with in vitro antibiotic susceptibilities or recognized activity (inhaled tobramycin) was then analysed for each patient treated. We considered the treatment as matching the antibiogram when the bacterial strain was fully susceptible to at least two antibiotics, or to at least one antibiotic if combined with inhaled tobramycin, because of the high expected local tobramycin concentrations.

\section{Microbiological outcome}

The microbiological follow-up allowed the classification of patients into two groups: "eradication", when the bacterium was not recovered over a follow-up period of at least 1 year including $\geq 3$ sputum cultures, and "persistence" in case of chronic colonisation. In the "persistence" group, the in vitro antibiotic susceptibility of the post-treatment isolate was compared to that of the pretreatment isolate.

\section{Statistical analysis}

After a verification phase in order to highlight missing, incorrect or inconsistent data, the database was locked, and information analysed. Characteristics were compared via the Chi2 test or Fisher's exact test using theoretical aspects for qualitative variables. Comparisons of quantitative variables were performed using the Student test, or the Mann-Whitney nonparametric test if the normality or homoscedasticity of the distributions had not been checked. Statistical tests were conducted with STATA v13.1, and were carried out using a bilateral approach and a type one error of 5\%. A value of $p<0.05$ was considered significant for all analyses.

\section{Results \\ General characteristics}

The general characteristics of the cohort are described in Table 1 . Seventeen patients (7 children < 18 years and 10 adults $\geq 18$ years) were included. At least four sputum cultures had been performed during the two previous years and were Burkholderia negative. The sex ratio $(M / F)$ was $1 / 0.3$. Most patients $(15 / 17)$ carried the F508del mutation, with a majority of heterozygotes (12/15). Median FEV1 at PC was $83 \%$ predicted and 7 patients had a FEV1 $\geq 90 \%$. During the 3 months preceding PC, 70.6\% (12/17) of patients had received antibiotic therapy due to clinical condition's deterioration, and $17.6 \%$ (3/17), systemic corticosteroids. Fourteen patients were colonised with BCC species, the most common species being B. multivorans (6 patients). Bacterial genotyping demonstrated that all BCC PC involved sporadic strains, with the exception of one epidemic strain of $B$. multivorans. Three patients were colonised with $B$. gladioli. A majority of patients $(12 / 17,70.6 \%)$ also harboured S. aureus, and 6/17 (35.3\%) P. aeruginosa.

\section{Eradication treatment modalities}

PC treatments and outcomes are detailed per patient in Table 2. Eleven out of 17 patients (64.7\%) underwent eradication therapy, including 4 out of 6 patients with $B$. multivorans, 4 out of 4 patients with $B$. cenocepacia, 2 out of 4 patients with other BCC species, and 1 out of 3 patients with B. gladioli. The median interval between $\mathrm{PC}$ and the onset of treatment was 38 days [range 5-98]. Treatment modalities were heterogeneous, including intravenous (IV), oral and nebulised antibiotics. All antibiotic regimens were combinations of two compounds or more and comprised an IV beta-lactam in 8 cases $(72.7 \%)$, combined with an IV (4) or inhaled (2) aminoglycoside and/or IV ciprofloxacin (3). Oral treatments (4 patients) included levofloxacin or ciprofloxacin and/or cotrimoxazole. Three patients received inhaled aztreonamlysine. The duration of all IV courses was 14 days, whereas that of oral treatments was 21 to 28 days. Lastly, the treatment matched antibiogram data in $54.5 \%$ of patients $(6 / 11)$. 
Table 1 Baseline characteristics of the 17 patients at Burkholderia primary colonisation

\begin{tabular}{|c|c|}
\hline Patient characteristics $(\boldsymbol{N}=17)$ & Number (percentage) or median value [min-max] \\
\hline Male gender & $13(76.5 \%)$ \\
\hline Age (years) & $19[6-34]$ \\
\hline CFTR genotype: F508del/F508del & $3(17.6 \%)$ \\
\hline F508del/other or unknown & $12(70.6 \%)$ \\
\hline Other or unknown & $2(11.8 \%)$ \\
\hline BMI (Z-score) & $-0.76[-2.81-0.39]$ \\
\hline Insulin-dependent diabetes & $3(17.6 \%)$ \\
\hline Exocrine pancreatic insufficiency & $16(94.1 \%)$ \\
\hline Nutritional support (gastrostomy/enteral tube) & $1(5.9 \%)$ \\
\hline Liver cirrhosis & $1(5.9 \%)$ \\
\hline ABPA & $3(17.6 \%)$ \\
\hline \multicolumn{2}{|l|}{ Respiratory function tests } \\
\hline Median FEV1 (\% predicted) & $83.0[26-113]$ \\
\hline Median FVC (\% predicted) & 92.0 [36-109] \\
\hline \multicolumn{2}{|l|}{ Burkholderia species } \\
\hline $\mathrm{BCC}$ & $14(82.4 \%)$ \\
\hline B. multivorans & $6(35.3 \%)$ \\
\hline B. cenocepacia ${ }^{a}$ & $4(23.5 \%)$ \\
\hline B. contaminans & $1(5.9 \%)$ \\
\hline B. vietnamiensis & $1(5.9 \%)$ \\
\hline B. ambifaria & $1(5.9 \%)$ \\
\hline Unidentified $\mathrm{BCC}^{\mathrm{b}}$ & $1(5.9 \%)$ \\
\hline B. gladioli & $3(17.6 \%)$ \\
\hline \multicolumn{2}{|l|}{ Co-pathogens } \\
\hline Methi-S Staphylococcus aureus & $7(41.2 \%)$ \\
\hline Methi-R Staphylococcus aureus & $5(29.4 \%)$ \\
\hline Pseudomonas aeruginosa & $6(35.3 \%)$ \\
\hline Fungi & $4(23.5 \%)$ \\
\hline Stenotrophomonas maltophilia & $3(17.6 \%)$ \\
\hline Non-tuberculous Mycobacteria & $2(11.8 \%)$ \\
\hline Achromobacter spp. & $0(0 \%)$ \\
\hline
\end{tabular}

CFTR Cystic Fibrosis Transmembrane conductance Regulator, BMI Body Mass Index, ABPA Allergic Broncho-Pulmonary Aspergillosis, FEV1 Forced Expiratory Volume in one second, FVC Forced Vital Capacity, BCC Burkholderia cepacia complex, Methi-S Methicillin-Susceptible, Methi-R Methicillin-Resistant

${ }^{a}$ including 3 cenocepacia IIIA and 1 cenocepacia IIIB subtypes

${ }^{b}$ on the basis of RecA sequencing results analysed using the Burkholderia cepacia complex MLST Databases website (https://pubmlst.org/bcc/), this isolate was confirmed as BCC, but could not be assigned to any of the BCC species described so far

\section{Outcomes}

The median duration of follow-up was 5.9 years [range 1.0-8.2]. There was no death, Burkholderiainduced septicaemia, nor cepacia syndrome to report. One patient underwent lung transplantation 2 years after PC. The Burkholderia strain was cleared in 10 patients, whereas infection was persistent in 7 patients. A comparison of patient characteristics in the two microbiological outcome groups is presented in Table 3. There was no significant difference in terms of gender, age, previous antibiotherapy, BMI, and bacterial species. FEV1 values at PC and 2 years after PC were lower in the "persistence" group than in the "eradication" group, but the difference did not reach statistical significance ( $p=0.12$ and $p=0.08$, respectively). No correlation was found between implementation of eradication therapy, its time of onset and microbiological outcome. Four of the 6 untreated patients spontaneously cleared the bacterium, which was isolated only once in 2 of these patients, as well as in $3 / 6$ treated patients. Eradication was obtained in 5/6 
Table 2 Individual characteristics, treatments and outcomes in 17 cases of Burkholderia primary colonisation

\begin{tabular}{|c|c|c|c|c|c|c|c|c|}
\hline $\begin{array}{l}\text { Patient } \\
\text { No. }\end{array}$ & Centre & $\begin{array}{l}\text { Burkholderia } \\
\text { Species }\end{array}$ & $\begin{array}{l}\text { Co- } \\
\text { pathogens }\end{array}$ & $\begin{array}{l}\text { Age } \\
\text { (years) }\end{array}$ & $\begin{array}{l}\text { FEV1\% } \\
\text { at PC }\end{array}$ & $\begin{array}{l}\text { Treatment (molecules, routes of administration } \\
\text { and duration) }\end{array}$ & $\begin{array}{l}\text { Consistency } \\
\text { antibiogram/ } \\
\text { antibiotic } \\
\text { therapy }^{\mathrm{a}}\end{array}$ & Outcome \\
\hline 1 & M & B. multivorans & MRSA, PA & 19 & 71 & $\begin{array}{l}\text { PO Levofloxacin and Cotrimoxazole } 21 \text { days; } \\
\text { INH Aztreonam } 28 \text { days }\end{array}$ & Yes (3/3) & Eradication \\
\hline 2 & M & B. multivorans & $\begin{array}{l}\text { MRSA, PA, } \\
\text { Fungi } \mathrm{e}^{\mathrm{e}}\end{array}$ & 23 & 79 & PO Cotrimoxazole; INH Aztreonam, 28 days & Yes $(2 / 2)$ & Eradication \\
\hline 3 & M & B. multivorans & $\begin{array}{l}\text { MSSA, } \\
\text { Fungie }^{e}\end{array}$ & 28 & 94 & IV Ceftazidime and Tobramycin, 14 days & No $(1 / 2)$ & Persistence \\
\hline $4^{b}$ & B & B. multivorans & MRSA & 13 & 31 & IV Ceftazidime and Gentamicin, 14 days & No $(1 / 2)$ & Persistence \\
\hline 5 & $\mathrm{~T}$ & B. multivorans & & 6 & 113 & Not treated & & Eradication $^{c}$ \\
\hline 6 & T & B. multivorans & $\begin{array}{l}\text { MSSA, PA, } \\
\text { Fungi }\end{array}$ & 21 & 105 & Not treated & & Persistence \\
\hline 7 & $\mathrm{~T}, \mathrm{~B}$ & $\begin{array}{l}\text { B. cenocepacia } \\
\text { IIIA }\end{array}$ & MRSA, Sten & 10 & 87 & IV Ceftazidime and Ciprofloxacin, 14 days & Yes $(2 / 2)$ & Eradication $^{c}$ \\
\hline 8 & M & $\begin{array}{l}\text { B. cenocepacia } \\
\text { IIIB }\end{array}$ & Sten, $\mathrm{MB}$ & 18 & 52 & PO Ciprofloxacin; INH Aztreonam, 28 days & No $(0 / 2)$ & Eradication ${ }^{c}$ \\
\hline 9 & $\mathrm{~T}$ & $\begin{array}{l}\text { B. cenocepacia } \\
\text { IIIA }\end{array}$ & $\begin{array}{l}\text { MRSA } \\
\text { PA }\end{array}$ & 19 & 59 & $\begin{array}{l}\text { IV Piperacillin-tazobactam and Ciprofloxacin, } 14 \\
\text { days }\end{array}$ & No $(1 / 2)^{d}$ & Persistence \\
\hline 10 & M & $\begin{array}{l}\text { B. cenocepacia } \\
\text { IIIA }\end{array}$ & PA & 22 & 62 & $\begin{array}{l}\text { IV Temocillin and Tobramycin, } 14 \text { days; PO } \\
\text { Cotrimoxazole, } 28 \text { days }\end{array}$ & Yes $(2 / 3)$ & Persistence \\
\hline 11 & M & B. contaminans & $\mathrm{PA}, \mathrm{MB}$ & 33 & 26 & Not treated & & Eradication $^{c}$ \\
\hline 12 & $\mathrm{~T}, \mathrm{M}$ & B. vietnamiensis & MSSA & 17 & 109 & Not treated & & Eradication \\
\hline 13 & B & B. ambifaria & MSSA & 7 & 83 & IV Ceftazidime and Tobramycin, 14 days & No $(1 / 2)$ & Persistence \\
\hline 14 & $\mathrm{~T}$ & $\begin{array}{l}\text { Unidentified } \\
\text { BCC }\end{array}$ & MSSA & 16 & 106 & $\begin{array}{l}\text { IV Ceftazidime and Ciprofloxacin; INH } \\
\text { Tobramycin, } 14 \text { days }\end{array}$ & Yes $(3 / 3)$ & Eradication $^{c}$ \\
\hline 15 & B & B. gladioli & MSSA & 14 & 112 & $\begin{array}{l}\text { IV Piperacillin-tazobactam; INH Tobramycin, } 14 \\
\text { days }\end{array}$ & Yes $(2 / 2)$ & Eradication \\
\hline 16 & $\mathrm{~T}$ & B. gladioli & Sten & 34 & 99 & Not treated & & Eradication \\
\hline 17 & $\mathrm{~T}$ & B. gladioli & $\begin{array}{l}\text { MSSA, } \\
\text { Fungi }^{e}\end{array}$ & 32 & 65 & Not treated & & Persistence \\
\hline
\end{tabular}

FEV1 Forced Expiratory Volume in one second, B Bordeaux, M Montpellier, $T$ Toulouse, BCC Burkholderia cepacia complex, MB Mycobacteria, MSSA, MethicillinSusceptible Staphylococcus aureus, MRSA Methicillin-Resistant Staphylococcus aureus, PA Pseudomonas aeruginosa, Sten Stenotrophomonas maltophilia, PO per os, IV intravenous, INH inhaled

${ }^{a}$ Consistency antibiogram/antibiotic therapy: in vitro full susceptibility to at least two of the antibiotics used, or to at least one antibiotic if combined with inhaled tobramycin. All BCC were resistant to IV aminoglycosides (natural resistance)

b This patient underwent lung transplantation and colonisation disappeared following surgery

c Single isolate

${ }^{d}$ The strain was only susceptible to ciprofloxacin

e Concerning fungi repartition: patient No 2 Aspergillus fumigatus; Patient No 3 Aspergillus spp.; Patient No 6 Candida albicans; Patient No 17 Aspergillus fumigatus and Candida albicans

patients receiving an antibiotic regimen which was in accordance with antibiogram data, and in only $1 /$ 5 patients otherwise $(p=0.08)$. It should be noted that beta-lactam/IV aminoglycosides combinations $(+/-$ another molecule) were associated with treatment failures in $4 / 4$ patients, even when the strain was susceptible to the beta-lactam used, whereas the two eradication regimens including inhaled tobramycin were successful. Five patients received combinations including a fluoroquinolone (ciprofloxacin or levofloxacin), which was active in vitro in 3 cases belonging to the "eradication" group (with $1 / 3$ single isolation), and inactive in 2 cases ( 1 in the "eradication" group with a single isolation, and 1 in the "persistence" group). Lastly, inhaled aztreonamlysine was associated with eradication in $3 / 3$ patients, with $2 / 3$ single isolations. Concerning the impact of treatment on antibiotic susceptibility, the analysis of post-treatment isolates in the 5 treated patients who developed chronic infection showed that $2 / 5$ isolates had become resistant to one of the antibiotics administered ( 1 to ciprofloxacin and 1 to cotrimoxazole), whereas beta-lactam susceptibilities were not significantly modified. 
Table 3 Compared patient data in the "eradication" and "persistence" groups. Results are expressed in numbers or mean \pm standard deviation

\begin{tabular}{|c|c|c|c|}
\hline Patient data & Eradication $(\boldsymbol{N}=10)$ & Persistence $(\boldsymbol{N}=7)$ & $\boldsymbol{p}$ value \\
\hline Male & 8 & 5 & 1 \\
\hline Age at PC (years) & $19.1 \pm 8.6$ & $20.2 \pm 8.0$ & 0.74 \\
\hline BMI (Z-score) at PC & $-1.04 \pm 0.8$ & $-0.62 \pm 0.6$ & 0.42 \\
\hline Antibiotics in the 3 months before PC & 9 & 3 & 0.1 \\
\hline \multicolumn{4}{|l|}{ Lung function (\% predicted) } \\
\hline FVC at PC & $92.8 \pm 15.6$ & $65.3 \pm 20.1$ & 0.11 \\
\hline FEV1 at PC & $85.4 \pm 27.4$ & $65.7 \pm 23.0$ & 0.12 \\
\hline FEV1 2 years after $P C^{a}$ & $77.7 \pm 26.1$ & $57.2 \pm 18.4$ & 0.08 \\
\hline \multicolumn{4}{|c|}{ Distribution of Burkholderia strains at PC } \\
\hline $\mathrm{BCC}$ & 8 & 6 & \\
\hline B. multivorans & 3 & 3 & 0.64 \\
\hline B. cenocepacia & 2 & 2 & 1 \\
\hline B. contaminans & 1 & 0 & 1 \\
\hline B. vietnamiensis & 1 & 0 & 1 \\
\hline B. ambifaria & 0 & 1 & 0.41 \\
\hline Unidentified BCC & 1 & 0 & 1 \\
\hline B. gladioli & 2 & 1 & 1 \\
\hline \multicolumn{4}{|l|}{ Antibiotic treatment } \\
\hline No treatment & 4 & 2 & 1 \\
\hline Eradication treatment & 6 & 5 & 1 \\
\hline Time to treat from the $P C$ (days) & $34 \pm 20.5$ & $48 \pm 37.9$ & 0.71 \\
\hline \multicolumn{4}{|c|}{ Consistency antibiogram/antibiotic therapy } \\
\hline Consistent $^{\mathrm{b}}$ & 5 & 1 & 0.08 \\
\hline Inconsistent & 1 & 4 & \\
\hline
\end{tabular}

BMI Body Mass Index, PC primary colonisation, FVC Forced Vital Capacity, FEV1 Forced Expiratory Volume in one second, BCC Burkholderia cepacia complex a Data unavailable for one patient with one-year follow-up,

${ }^{b}$ in vitro full susceptibility to at least two of the antibiotics used, or to at least one antibiotic if combined with inhaled tobramycin

\section{Discussion}

Though limited to 5 of the 40 French CF Centres following Burkholderia-positive patients, our retrospective study demonstrated a great diversity in the management of initial colonisations with BCC or B. gladioli.

\section{Should eradication therapy be systematically implemented?}

In the present series, eradication was not systematically attempted, as related by Horsley et al. in their survey of adult CF Centres in UK [26]. Indeed, while in the epidemic era, most infections with BCC persisted over years, nowadays infection is transient in about $50 \%$ of French patients [6]. As regards B. gladioli, Kennedy et al. showed a transient colonisation rate of $60 \%$ in a series of 30 North American patients [16], similar to that observed in France [17]. In the present study, spontaneous clearance was observed in 4 out of 6 untreated patients, and in the 3 treated patients with only one positive sputum culture, we cannot be sure that the bacterium would not have been cleared without antibiotic therapy, as pointed out by Horsley et al. in their study [26]. These observations could lead to discuss a short follow-up of sputum cultures before introducing eradication therapy in some patients whose characteristics have yet to be defined in greater detail.

Some risk factors for progressing towards chronic colonisation have been proposed. In a study including 64 patients in Australia, Ramsay et al. reported a significantly higher risk of chronic infection in adults than in children [27]. However, in our small cohort, patients in the «persistence» group were not significantly older than those in the "eradication" group. Folescu et al. studied BCC infections in 27 Brazilian patients chronically colonised with $P$. aeruginosa and pointed out a correlation between a low BMI and chronic colonisation [28]. The major difference, though not statistically significant, between our two groups was a lower FEV1 value in case of "persistence", which agrees with the poorer lung function at PC observed in adult patients with chronic 
infection by Ramsay et al. [27]. Thus, age and degree of severity of the disease (FEV1 and BMI) at the time of Burkholderia acquisition may have an influence on the success of $\mathrm{BCC}$ eradication treatment.

\section{Burkholderia species and outcomes}

Another question is whether approaches to new infections ought to be adjusted according to the species detected, with regard to the ability to be involved in chronic infection, as well as to potential virulence. In Canada, Zlosnik et al. reported a higher rate of transient infection in patients harbouring $B$. multivorans (55\%) or $B$. vietnamiensis $(44 \%)$, than in patients harbouring $B$. cenocepacia (19\%). In the present study, the effect of the Burkholderia species on progression to chronic colonisation could not be established given the considerable diversity of the species and the limited number of patients. As regards the clinical impact of infection, the poor outcomes generally associated with $B$. cenocepacia may be partly due to the spread of highly virulent clones in the 1990s, and B. multivorans, which is considered to be less virulent than $B$. cenocepacia in most countries, was also responsible for severe infections in French patients (OBC data), [29]. Thus, species-adjusted eradication therapy implementation should take account of national, or even local epidemiology, and defining the attitude to infection with rare species is expected to be difficult. Concerning transplantation-associated risks, B. cenocepacia and B. gladioli are considered to be the most problematic species and constitute a relative contraindication to lung transplantation. However, we also observed post-transplant bloodstream infections due to $B$. multivorans and $B$. vietnamiensis (OBC data), which does not allow to rule out any risk in case of colonisation with other species. In our study, eradication was attempted in 4 out of 4 patients with B. cenocepacia, but in only 1 out of 3 patients with B. gladioli, and in 6 out of 10 patients with other species. To-date, there is no evidence clearly establishing the benefit of early eradication therapy [18] and our study failed to demonstrate the superiority of attempted eradication over therapeutic abstention. Nevertheless, as discussed above, it can be assumed that eradication treatment is relevant in patients whose infection is most likely to become chronic, namely those with the most severe forms of the disease at detection, and/or in patients colonised by given species.

Is in vitro antibiotic susceptibility testing useful to choose an eradication protocol?

Antibiotic regimens were heterogeneous, including IV, oral and nebulised antibiotics. Such heterogeneity was also reported in the UK survey by Horsley et al. [26], and within published studies. Kitt et al. successfully proposed tobramycin, temocillin and ceftazidime IV combination therapy for 14 days followed by a switch to tobramycin aerosols for 3 months in 2 children ( 1 B. gladioli and 1 B. cepacia) [30]. Uluer et al. reported 12 failed attempts at eradication of $B$. dolosa following the administration of amiloride and tobramycin aerosols for 6 months [31]. Using the same treatment, Ball et al. recorded 6 therapeutic failures in 7 children treated (eradication of B. stabilis, persistence of $3 \mathrm{~B}$. multivorans and 3 B. cenocepacia) [32]. Among 14 treated patients, Horsley et al. reported 4 successful eradications based on 14 days of IV antibiotic therapy comprising tobramycin and meropenem with the addition of trimethoprim-sulfamethoxazole $(n=4)$, ceftazidime $(n=5)$ and chloramphenicol $(n=2)$. Antibiotics were also administered via a nebuliser (tobramycin or meropenem) on 13 occasions, generally for 12 weeks [26]. Lastly, Garcia et al. proposed a standardized aggressive protocol comprising a 21-day induction stage (IV + inhaled tobramycin, cetazidime, trimethoprim-sulfamethoxazole) and a 2 months consolidation stage (trimethoprim-sulfamethoxazole, inhaled tobramycin), combined with long-term azithromycin as anti-inflammatory [33]. However, due to the low numbers of patients and the diversity of patient populations and treatment protocols, the best antibiotic strategy is not defined to date [18]. Burkholderia species are innately resistant to many antibiotics including some of those used to treat Pseudomonas aeruginosa such as aminoglycosides and colistine, and additional resistance may appear during antibiotic therapy, as observed in 2 of our 11 treated patients. Hence, the treatment of colonisations and infections with Burkholderia is particularly difficult and based on a small number of molecules mostly used in combination to limit resistance selection. These currently comprise meropenem, ceftazidime, temocillin, cotrimoxazole, ciprofloxacin or cyclines [34]. $\mathrm{BCC}$ is usually considered to be resistant to aztreonam, but some strains are susceptible, and Iglesias et al. reported successful eradication of BCC in two patients with bronchiectasis following inhaled aztreonam lysine courses [35]. The latest ceftazidime-avibactam combination therapy seems promising but insufficient clinical experience has been acquired to date [36]. In spite of the natural resistance to aminoglycosides, the use of inhaled tobramycin which allows the delivery of high doses are considered to be of interest in BCC infections [24, 25]. B. gladioli is generally slightly more susceptible than $\mathrm{BCC}$, especially to piperacillin-tazobactam and aminoglycosides [17]. The European Committee on Antimicrobial Susceptibility Testing (EUCAST) does not currently advocate Burkholderia susceptibility testing as a guideline for antibiotic therapy given the lack of any obvious correlation between in vitro susceptibility and the patient's clinical course [19]. Conversely, both the Clinical 
and Laboratory Standards Institute (CLSI) and the antibiogram committee of the French Society for Microbiology provide specific guidelines for a limited number of molecules. In our study, consistency between treatment and antibiotic susceptibility appears to be associated with improved microbiological efficacy, since eradication was achieved in 5/6 cases (83.3\%) of antibiogram consistency versus $1 / 5$ cases (20\%) of inconsistency.

\section{Limitations and perspectives}

The present study has several limitations, due to the low number of patients, the diversity of species involved as well as of therapeutic approaches, leading to insufficient statistical power. Thus, the positive impact of successful eradication on lung function did not reach statistical significance. Though our results suggest that the antibiogram may be of interest in order to guide therapeutic choices on a case-by-case basis, establishing the relevance of in vitro testing suffers from poor and controversial definition of clinical breakpoints, and from insufficient data. Therefore, we plan to launch a nationwide retrospective study, which is expected to provide further information and improve statistical relevance.

Moreover, the lack of standardisation in retrospective studies is a potential source of bias. Due to the heterogeneity of the population of CF patients, clinical trials assessing different treatment protocols will probably be required to determine management algorithms considering all clinical and microbiological situations (extent of pulmonary impairment, Burkholderia species, copathogens). Based on our results and the literature, testing a triple therapy comprising an IV beta-lactam (ceftazidime or meropenem), an oral or IV fluoroquinolone (ciprofloxacin or levofloxacin) plus an inhaled aminoglycoside (tobramycin), and checking for consistency between this protocol and the resistance profile of the isolated strain should be considered when designing such trials. In case of $B$. gladioli colonisation, piperacillin-tazobactam or meropenem could be preferred to ceftazidime owing to their higher in vitro activity $[17,36]$. In children, trimethoprim-sulfamethoxazole represents an alternative to quinolones. IV/oral treatments could be administered during 2 to 3 weeks whereas longer durations ( 8 to 12 weeks) could be proposed for inhaled treatments $[26,33]$. Lastly, given the specific pharmacodynamic profile of CF subjects, antibiotic assays should be encouraged for the purpose of dose optimisation. Given the low incidence of the Burkholderia infection in CF patients, only large-scale multicentre studies can shed light on this issue.

\section{Conclusion}

The present retrospective pilot study in five French CF Centres highlighted the heterogeneity of therapeutic management of initial infections with Burkholderia species. Though not statistically significant, treatment efficacy tended to be related to a better lung function at $\mathrm{PC}$, and to consistency with in vitro antibiotic activity. A nation-wide study is required to evaluate the relevance of these preliminary results. Based on our observations, we suggest the implementation and evaluation of a triple eradication therapy comprising an IV beta-lactam: meropenem, or ceftazidime (BCC), or piperacillin-tazobactam (B. gladioli), an oral or IV fluoroquinolone (ciprofloxacin) and an inhaled aminoglycoside (tobramycin). Owing to potential spontaneous clearance, a follow-up sputum culture can be discussed prior to introducing treatment in milder cases. Large-scale studies are required to standardise Burkholderia PC treatment in CF patients.

\section{Abbreviations}

ABPA: Allergic broncho-pulmonary aspergillosis; BCC: Burkholderia cepacia complex; BMI: Body mass index; CF: Cystic fibrosis; FEV1: Forced expiratory volume in one second; FVC: Forced vital capacity; IV: Intravenous;

OBC: Observatoire Burkholderia cepacia; PC: Primary colonisation

\section{Acknowledgements}

Not applicable.

\section{Authors' contributions}

VG designed the work, made acquisition, analysis, interpretation of data and drafted the work. HGR designed the work, made analysis, interpretation of data and substantively revised the work. CS made interpretation of data, and substantively revised the work. SB helped for acquisition and substantively revised the work. JM helped for acquisition and substantively revised the work. RC helped for acquisition and substantively revised the work. MMic substantively revised the work. MME substantively revised the work. MMit designed the work, made interpretation of data and substantively revised the work. All authors read and approved the final manuscript.

\section{Funding}

This research did not receive any specific grant from funding agencies in the public, commercial, or not-for-profit sectors.

\section{Availability of data and materials}

The datasets used and/or analysed during the current study are available from the corresponding author on reasonable request.

Ethics approval and consent to participate

The data collection process was reported to the Commission Nationale Informatique et Liberté (French Data Protection Authority) on 26/01/2018, under number $2146344 \mathrm{v} 0$. No formal consent was necessary to participate in the study.

Consent for publication

Not applicable.

\section{Competing interests}

The authors declare that they have no competing interests.

\section{Author details}

${ }^{1}$ CRCM pédiatrique, Service de Pneumo-Allergologie pédiatrique, Hôpital des Enfants, Centre Hospitalier Universitaire de Toulouse, 330 avenue de Grande-Bretagne - TSA 40031, 31059 Toulouse cedex 9, France. ${ }^{2}$ Service de Bactériologie-Hygiène, Centre Hospitalier Universitaire de Toulouse, Toulouse, France. ${ }^{3}$ Observatoire Burkholderia cepacia, Centre Hospitalier Universitaire de Toulouse, Toulouse, France / Vaincre la Mucoviscidose, Paris, France. ${ }^{4} \mathrm{CRCM}$ pédiatrique, Service de pédiatrie médicale, Centre Hospitalier Universitaire de Bordeaux-GH Pellegrin, Bordeaux, France. ${ }^{5}$ Service de pneumologie, Centre Hospitalier Universitaire de Bordeaux-GH Sud - Hôpital Haut-Lévêque, Pessac, France. ${ }^{6} \mathrm{CRCM}$ pédiatrique, Service des maladies 
respiratoires, Centre Hospitalier Universitaire de Montpellier - Hôpital Arnaud de Villeneuve, Montpellier, France. ${ }^{7}$ Service de pneumologie - Consultation Mucoviscidose, Pôle voies respiratoires, Centre Hospitalier Universitaire de Toulouse - Hôpital Larrey, Toulouse, France.

\section{Received: 6 July 2019 Accepted: 19 May 2020}

Published online: 05 June 2020

\section{References}

1. Tablan OC, Martone WJ, Doershuk CF, Stern RC, Thomassen MJ, Klinger JD, White JW, Carson LA, Jarvis WR. Colonization of the respiratory tract with Pseudomonas cepacia in cystic fibrosis: risk factors and outcomes. Chest. 1987;91(4):527-32. https://doi.org/10.1378/chest.91.4.527.

2. Olland A, Falcoz PE, Kessler R, Massard G. Should cystic fibrosis patients infected with Burkholderia cepacia complex be listed for lung transplantation? Interact Cardiovasc Thorac Surg. 2011;13(6):631-4. https:// doi.org/10.1510/icvts.2011.271874.

3. Zlosnik J, Zhou G, Brant R, Henry D, Hird T, Mahenthiralingam E, Chilvers M, Wilcox P, Speert D. Burkholderia species infections in patients with cystic fibrosis in British Columbia, Canada. 30 years' experience. Ann Am Thorac Soc. 2015;12(1):70-8. https://doi.org/10.1513/AnnalsATS.201408-395OC.

4. Salsgiver EL, Fink AK, Knapp EA, LiPuma JJ, Olivier KN, Marshall BC, Saiman L. Changing epidemiology of the respiratory bacteriology of patients with cystic fibrosis. Chest. 2016;149(2):390-400. https://doi.org/ 10.1378/chest.15-0676

5. Kenna DTD, Lilley D, Coward A, Martin K, Perry C, Pike R, Hill R, Turton JF. Prevalence of Burkholderia species, including members of Burkholderia cepacia complex, among UK cystic and non-cystic fibrosis patients. J Med Microbiol. 2017;66(4):490-501. https://doi.org/10.1099/jmm.0.000458.

6. Segonds C, Guet-Revillet H, Dehillotte C, Lemonnier L. Rapport épidémiologique. Paris: Observatoire Cepacia et Registre français de la mucoviscidose; 2014. https://www.registredelamuco.org.

7. Nunvar J, Kalferstova L, Bloodworth RAM, Kolar M, Degrossi J, Lubovich S, Cardona ST, Drevinek P. Understanding the pathogenicity of Burkholderia contaminans, an emerging pathogen in cystic fibrosis. PLoS One. 2016;11(8): e0160975. https://doi.org/10.1371/journal.pone.0160975.

8. Coutinho CP, Dos Santos SC, Madeira A, Mira NP, Moreira AS, Sa-Correia I. Long-term colonization of the cystic fibrosis lung by Burkholderia cepacia complex bacteria: epidemiology, clonal variation, and genome-wide expression alterations. Front Cell Infect Microbiol. 2011;1:12. https://doi.org/ 10.3389/fcimb.2011.00012.

9. Medina-Pascual MJ, Valdezate S, Villalon P, Garrido N, Rubio V, Saez-Nieto JA. Identification, molecular characterisation and antimicrobial susceptibility of genomovars of the Burkholderia cepacia complex in Spain. Eur J Clin Microbiol Infect Dis. 2012;31(12):3385-96. https://doi.org/10.1007/s10096012-1707-6.

10. Jones A, Dodd M, Govan J, Barcus V, Doherty C, Morris J, Webb A. Burkholderia cenocepacia and Burkholderia multivorans: influence on survival in cystic fibrosis. Thorax. 2004;59(11):948-51. https://doi.org/10.1136/thx. 2003.017210.

11. Boussaud V, Guillemain R, Grenet D, Coley N, Souilamas R, Bonnette P, Stern M. Clinical outcome following lung transplantation in patients with cystic fibrosis colonised with Burkholderia cepacia complex: results from two French centres. Thorax. 2008;63(8):732-7. https://doi.org/10.1136/thx.2007. 089458.

12. Kalish LA, Waltz DA, Dovey M, Potter-Bynoe G, McAdam AJ, Lipuma J. Gerard C, Goldmann D. Impact of Burkholderia dolosa on lung function and survival in cystic fibrosis. Am J Respir Crit Care Med. 2006;173(4):421-5. https://doi.org/10.1164/rccm.200503-344OC.

13. LiPuma JJ, Dasen SE, Nielson DW, Stern RC, Stull TL. Person-to-person transmission of Pseudomonas cepacia between patients with cystic fibrosis. Lancet. 1990;336(8723):1094-6. https://doi.org/10.1016/01406736(90)92571-X

14. Govan JR, Brown PH, Maddison J, Doherty CJ, Nelson JW, Dodd M, Greening AP, Webb AK. Evidence for transmission of Pseudomonas cepacia by social contact in cystic fibrosis. Lancet. 1993;342(8862):15-9. https://doi. org/10.1016/0140-6736(93)91881-L.

15. Segonds C, Bingen E, Couetdic G, Mathy S, Brahimi N, Marty N, Plesiat P, Michel-Briand Y, Chabanon G. Genotypic analysis of Burkholderia cepacia isolates from 13 cystic fibrosis centers. J Clin Microbiol. 1997;35(8):2055-60.
16. Kennedy M, Coakley R, Donaldson S, Aris R, Hohneker K, Wedd J, Knowles M, Gilligan P, Yankaskas J. Burkholderia gladioli: five year experience in a cystic fibrosis and lung transplantation center. J Cyst Fibros. 2007;6(4):26773. https://doi.org/10.1016/j.jcf.2006.10.007.

17. Segonds C, Clavel-Batut P, Thouverez M, Grenet D, Le Coustumier A, Plesiat $P$, Chabanon G. Microbiological and epidemiological features of clinical respiratory isolates of Burkholderia gladioli. J Clin Microbiol. 2009;47(5):15106. https://doi.org/10.1128/jcm.02489-08.

18. Regan KH, Bhatt. Eradication therapy for Burkholderia cepacia complex in people with cystic fibrosis. Cochrane Database Syst Rev. (4). https://doi.org/ 10.1002/14651858.CD009876.pub4.

19. EUCAST (2013) Guidance Documents in susceptibility testing Antimicrobial susceptibility testing of Burkholderia cepacia complex (BCC) http://www. eucast.org/fileadmin/src/media/PDFs/EUCAST_files/General_documents/ BCC_susceptibility_testing_130719.pdf.

20. Société française de Microbiologie. Diagnostic microbiologique des sécrétions broncho-pulmonaires chez un patient mucoviscidosique. Paris: Référentiel de Microbiologie Médicale; 2010.

21. Segonds C, Heulin T, Marty N, Chabanon G. Differentiation of Burkholderia species by PCR-restriction fragment length polymorphism analysis of the 165 rRNA gene and application to cystic fibrosis isolates. J Clin Microbiol. 1999;37(7):2201-8

22. Baldwin A, Mahenthiralingam E, Thickett KM, Honeybourne D, Maiden MC, Govan JR, Speert DP, Lipuma JJ, Vandamme P, Dowson CG. Multilocus sequence typing scheme that provides both species and strain differentiation for the Burkholderia cepacia complex. J Clin Microbiol. 2005; 43(9):4665-73. https://doi.org/10.1128/JCM.43.9.4665-4673.2005.

23. Société française de Microbiologie. Comité de l'antibiogramme de la Société Française de Microbiologie/EUCAST (2018) Recommandations 2018 V.2.0 Septembre. https://www.sfm-microbiologie.org/wp-content/uploads/2 018/12/CASFMV2_SEPTEMBRE2018.pdf.

24. Kennedy S, Beaudoin T, Yau YCW, Caraher E, Zlosnik JEA, Speert DP, LiPuma $\mathrm{JJ}$, Tullis E, Waters V. Activity of tobramycin against cystic fibrosis isolates of Burkholderia cepacia complex grown as biofilms. Antimicrob Agents Chemother. 2015;60(1):348-55. https://doi.org/10.1128/AAC.02068-15.

25. Chmiel JF, Aksamit TR, Chotirmall SH, Dasenbrook EC, Elborn JS, LiPuma JJ, Ranganathan SC, Waters VJ, Ratjen FA. Antibiotic management of lung infections in cystic fibrosis. I. the microbiome, methicillin-resistant Staphylococcus aureus, gram-negative bacteria, and multiple infections. Ann Am Thorac Soc. 2014;11(7):1120-9. https://doi.org/10.1513/AnnalsATS. 201402-050AS.

26. Horsley A, Webb K, Bright-Thomas R, Govan J, Jones A. Can early Burkholderia cepacia complex infection in cystic fibrosis be eradicated with antibiotic therapy? Front Cell Infect Microbiol. 2011;1:18. https://doi.org/10. 3389/fcimb.2011.00018.

27. Ramsay KA, Butler CA, Paynter S, Ware RS, Kidd TJ, Wainwright CE, Bell SC. Factors influencing Acquisition of Burkholderia cepacia complex organisms in patients with cystic fibrosis. J Clin Microbiol. 2013;51(12):3975-80. https:// doi.org/10.1128/JCM.01360-13.

28. Folescu TW, da Costa CH, Cohen RWF, da Conceicao Neto OC, Albano RM, Marques EA. Burkholderia cepacia complex: clinical course in cystic fibrosis patients. BMC Pulm Med. 2015;15:158. https://doi.org/10.1186/s12890-015-0148-2.

29. Fauroux B, Hart N, Belfar S, Boulé M, Tillous-Borde I, Bonnet D, Bingen E, Clément A. Burkholderia cepacia is associated with pulmonary hypertension and increased mortality among cystic fibrosis patients. J Clin Microbiol. 2004:42(12):5537-41. https://doi.org/10.1128/JCM.42.12.5537-5541.2004.

30. Kitt H, Lenney W, Gilchrist FJ. Two case reports of the successful eradication of new isolates of Burkholderia cepacia complex in children with cystic fibrosis. BMC Pharmacol Toxicol. 2016;17:14. https://doi.org/10.1186/s40360016-005 $4-0$.

31. Uluer AZ, Waltz DA, Kalish LA, Adams S, Gerard C, Ericson DA. Inhaled amiloride and tobramycin solutions fail to eradicate Burkholderia dolosa in patients with cystic fibrosis. J Cyst Fibros. 2013;12(1):54-9. https://doi.org/10. 1016/j.jcf.2012.06.006.

32. Ball R, Brownlee KG, Duff AJA, Denton M, Conway SP, Lee TWR. Can Burkholderia cepacia complex be eradicated with nebulised Amiloride and TOBI? J Cyst Fibros. 2010;9(1):73-4. https://doi.org/10.1016/j.jcf.2009.11.001.

33. Garcia B, Carden J, Goodwin D, Smith T, Gaggar A, Leon K, Antony V, Rowe $\mathrm{S}$, Solomon G. Implementation of a successful eradication protocol for Burkholderia Cepacia complex in cystic fibrosis patients. BMC Pulm Med. 2018;18(1):35. https://doi.org/10.1186/s12890-018-0594-8. 
34. Abbott I, Peleg A. Stenotrophomonas, Achromobacter, and nonmelioid Burkholderia species: antimicrobial resistance and therapeutic strategies. Semin Respir Crit Care Med. 2015;36(1):99-110. https://doi.org/10.1055/s0034-1396929.

35. Iglesias A, Artiles I, Cabanillas JJ, Alvarez-Sala R, Prados C. Eradication of Burkholderia cepacia using inhaled Aztreonam lysine in two patients with bronchiectasis. Case Rep Pulmonol. 2014;2014:192146. https://doi.org/10. 1155/2014/192146.

36. Massip C, Mathieu C, Gaudru C, Miaut V, Floch P, Oswald E, Segonds C, Guet-Revillet $H$. In vitro activity of seven $\beta$-lactams including ceftolozane/ tazobactam and ceftazidime/avibactam against Burkholderia cepacia complex, Burkholderia gladioli and other non-fermentative gram-negative bacilli isolated from cystic fibrosis patients. J Antimicrob Chemother. 2019; 74(2):525-8. https://doi.org/10.1093/jac/dky423.

\section{Publisher's Note}

Springer Nature remains neutral with regard to jurisdictional claims in published maps and institutional affiliations.

- fast, convenient online submission

- thorough peer review by experienced researchers in your field

- rapid publication on acceptance

- support for research data, including large and complex data types

- gold Open Access which fosters wider collaboration and increased citations

- maximum visibility for your research: over $100 \mathrm{M}$ website views per year

At $\mathrm{BMC}$, research is always in progress. 